\title{
Preparation and Characterization Silver Nanoparticle Embedded Polyamide Nanofiltration (NF) Membrane
}

\author{
Tengku Anisa Tengku Sallehudin ${ }^{1}$, Mazrul Nizam Abu Seman ${ }^{1, *}$, and Syed Mohd Saufi Tuan Chik ${ }^{1}$ \\ ${ }^{1}$ Faculty of Chemical and Natural Resources Engineering, Universiti Malaysia Pahang, 26300 Kuantan, Pahang, Malaysia
}

\begin{abstract}
In this study, silver nanoparticles (AgNPs) were synthesized from tea leaves extract and its antimicrobial properties was tested on Escherichia coli $(E$. coli) using agar well method. The synthesized nanoparticles were characterized by using UV-vis spectroscopy, transmission electron microscopy (TEM) and X-ray diffraction (XRD). The result from XRD analysis shows that the synthesized AgNPs are a face-centered cubic (fcc) structure with an average particle size of $28 \pm 15$ $\mathrm{nm}$ AgNPs which confirmed by TEM. The synthesized AgNPs were then used in the preparation of thin film composite NF membrane via interfacial polymerization method. Separation performance of the produced membrane was evaluated in term of membrane permeability and solute rejection (vitamin $\mathrm{B} 12, \mathrm{NaCl}$ and $\mathrm{Na}_{2} \mathrm{SO}_{4}$ solutions). Based on the structural parameters (pore size, $r_{p}$ and $\Delta x / A_{k}$ ) values obtained from vitamin $\mathrm{B} 12$ test, all membranes can be considered as tight NF membranes. From the salts rejection test, membranes with the addition of AgNPs exhibited higher salt rejection compared to the neat membranes.
\end{abstract}

\section{Introduction}

Nowadays, applications of membrane separation have many advantages but their disadvantages also become a huge issue. Despite the widely uses in separation processes, membrane process faces a common problem namely fouling. Fouling could affect the membrane performance including flux and selectivity. In normal practice, to restore the membrane performance, physical and chemical cleaning approaches are applied. Besides that, membrane properties also not less important to be taken into consideration since it also may help minimizing the fouling problem.

One of the popular methods is by embedded the hydrophilic nanoparticles in membrane matrix in order to change the membrane surface properties, hence, reduce fouling. The common nanoparticles used to reduce fouling (especially biofouling against bacteria) are silver $(\mathrm{Ag})$ and titanium oxide $\left(\mathrm{TiO}_{2}\right) . \mathrm{TiO}_{2}$ selfassembled thin film composite membrane could only work effectively by an assistant of UV illumination where the additional energy required for UV light system (increase operational cost) [1]. As an alternative, $\mathrm{Ag}$ self-assembled membrane could be produced for antibacterial properties without extra cost (energy for UV light). Few studies have reported that AgNPs were used to synthesize low biofouling UF membranes by phase inversion method [2-5]. Ag self-assembled UF membrane synthesized by phase inversion was very efficient against bacteria. However, it was found that this type of membrane facing a problem with depletion of silver from membrane surface [2]. In the previous report, Lee et al. prepared polyamide NF membrane consisting commercial AgNPs by in situ interfacial polymerization method between aqueous MPhenylenediamine (MPD) and organic Trimesoyl Chloride (TMC)-Ag solutions and tested its antibiofouling effect on bacteria Pseudomonas [6]. Chemical reaction method was employed to synthesize AgNPs in the presence of stabilizing agent to prevent the unwanted colloids agglomeration. However, AgNPs from chemical synthesis are considered hazardous to the environment, expensive and consume high energy [710]. In order to overcome this problem, AgNPs was synthesized by the green method as it was simple and cost effective technique [11]. Tea leaf extract (Camellia sinensis) has been used to synthesize AgNP since it contains polyphenols and terpenoids, such as $\beta$ cariophyllene, linalool, cis-jasmone, $\alpha$-terpineol, $\delta$ cadiene, indole, geraniol, among the major biocomponents, which have bactericidal and antioxidant activity, and several other useful properties $[12,13]$. Here, we report on the preparation and characterization of low biofouling thin film composite polyamide NF membrane by interfacial polymerization method between organic TMC and aqueous MPD solution consisting AgNPs synthesized by greener method.

\section{Methodology}

\subsection{Materials}

Silver nitrate was obtained from Sigma Aldrich. Nutrient broth and Mueller Hinton agar powder, a product of Oxoid were supplied by Thermo Scientific. Dry tea leaves were bought from Malaysia tea plantations. The strain employed throughout this study Escherichia coli

\footnotetext{
*Corresponding author: mazrul@ump.edu.my
} 
(0157:H7) (ATCC 43888) was obtained from Central Laboratory University Malaysia Pahang (UMP). It was cultured on nutrient agar slants and kept at $4^{\circ} \mathrm{C}$. The commercially available Polyethersulfone Ultrafiltration (UFPES50) flat-sheet membrane (Nominal MWCO: $50 \mathrm{kDa}$ ) was supplied by Amfor Inc (China) and used as a substrate for thin film composite NF membrane. Both M-Phenylenediamine (MPD) and Trimesoyl Chloride (TMC) were supplied by Acros. N-hexane used as the organic phase solvent was obtained from Hamburg Industries Inc.

\subsection{Production of Silver Nanoparticles (AgNPs)}

\subsubsection{Preparation of tea extract}

To prepare the tea extract, $5 \mathrm{~g}$ of ground tea leaves was boiled in $500 \mathrm{ml}$ distilled water, and the beaker was thoroughly agitated for 1 hour using a heated stirrer and left to settle. The extract solution is then filtered through a $0.2 \mu \mathrm{m}$ membrane filter and used for further experiments.

\subsubsection{Synthesis of AgNPs}

Firstly, a dilute solution of silver nitrate $(0.1 \mathrm{M})$ was prepared by dissolving $1.6980 \mathrm{~g} \mathrm{AgNO}_{3}$ in $100 \mathrm{ml}$ distilled water. To carry out the reaction, $2 \mathrm{ml}$ of $0.1 \mathrm{M}$ $\mathrm{AgNO}_{3}$ was mixed with $10 \mathrm{ml}$ of tea extract solution and stirred at a constant speed at room temperature $\left(25^{\circ} \mathrm{C}\right)$, to ensure thorough mixing for about 24 hours. Any colour changes were observed.

\subsubsection{Washing process of AgNPs}

A desktop centrifuge was used in the washing process of AgNPs synthesized from the tea extract. The washing process could guarantee that the unreacted polyphenol content is removed from the AgNPs for purification. The AgNPs were separated and concentrated by repetition of 4 to 5 times mixture centrifugation at $2633 \times \mathrm{g}$ for 20 minutes. The supernatant was washed by distilled water each time.

\subsection{Characterizations of AgNPs}

\subsubsection{UV-Vis}

AgNPs in tea extract solution was first characterized by using UV-Vis spectrophotometer (Hitachi U-1800). UVVis spectrophotometer with a resolution of $1 \mathrm{~nm}$ between 300-800 $\mathrm{nm}$ possessing a scanning speed of $300 \mathrm{~nm} / \mathrm{min}$ was used. The reduction of pure $\mathrm{Ag}^{+}$ions was monitored by measuring the UV-Vis spectrum of the reaction medium after diluting a small aliquot of the sample with deionized water. One millilitre $(1 \mathrm{ml})$ of the sample was pipetted into a test tube and diluted with 4 $\mathrm{ml}$ of distilled water and subsequently analysed at room temperature.

\subsubsection{TEM}

Investigation of the size and morphology of the AgNPs were carried out under a transmission electron microscope, TEM (Hitachi H7100) with an accelerating voltage of $120 \mathrm{kV}$. A drop of the silver nanoparticles solution was deposited onto a carbon-coated copper grid and was allowed to evaporate at room temperature. The size distribution of the AgNPs was based on diameter measurement of $>200$ particles on TEM micrographs using image analysis software I-Solution (IMT).

\subsection{3 $X R D$}

The x-ray diffraction (XRD) analysis was carried out using Rigaku Miniflex II software $\theta-2 \theta$ diffractometer with $\mathrm{Cu}, \mathrm{K}_{\alpha}$ radiation at $30 \mathrm{kV}, 15 \mathrm{~mA}$ and wavelength $(\lambda)=1.54056 \AA$. Scans were typically in the range $10-70^{\circ}$ $2 \theta$, with $0.02^{\circ}$ step sizes that were held for 2 seconds each.

\subsection{Thin Film Composite (TFC) Membrane}

\subsubsection{Preparation of PA and PA/Ag Membranes}

The polyamide (PA) membrane was prepared by interfacial polymerization on the surface of commercial UFPES membrane support layer between $2 \%$ w/v MPD and $0.15 \% \mathrm{w} / \mathrm{v}$ TMC as described in our previous report [14]. For silver nanoparticles polyamide (PA/Ag) membrane preparation, $20 \mathrm{ml}$ of $3 \mathrm{~g} / \mathrm{L}(3000 \mu \mathrm{g} / \mathrm{ml})$ neat silver nanoparticles colloids (produced as described in section 2.2) then added to $80 \mathrm{ml}$ MPD aqueous solution making the final concentration of AgNPs in the $100 \mathrm{ml}$ of mixture aqueous solution (MPD + AgNPs) was $0.6 \mathrm{mg} / \mathrm{L}$. Overall, six different types of NF membranes were prepared at different reaction time and summarized in Table 1 .

Table 1. Preparation of NF membranes

\begin{tabular}{ccc}
\hline $\begin{array}{c}\text { Types of } \\
\text { Membrane }\end{array}$ & $\begin{array}{c}\text { \#AgNPs } \\
\text { loading } \\
(\mathrm{ml})\end{array}$ & $\begin{array}{c}\text { Reaction } \\
\text { Time }(\mathrm{s})\end{array}$ \\
\hline PA-10 & - & 10 \\
PA-30 & - & 30 \\
PA-60 & - & 60 \\
PA/Ag-10 & 20 & 10 \\
PA/Ag-30 & 20 & 30 \\
PA/Ag-60 & 20 & 60 \\
\hline
\end{tabular}

\# $20 \mathrm{ml}$ is an optimum AgNPs loading as reported in [14].

\subsubsection{Antibacterial assay of PA/Ag membrane}

Antibacterial activity of the prepared membranes was investigated by agar diffusion method against E.coli. Kirby Bauer technique was applied in the preparation of media-culture plate containing E.coli. The media agar used was purchased from Merck. The membranes were cut into circular-disks, autoclaved and put on the bacteria media-culture at $37^{\circ} \mathrm{C}$ incubation temperature overnight. 
The antibacterial activity of the membrane was determined by inhibition ring that formed after $24 \mathrm{~h}$ incubation. The growth inhibition was visually detected on the next day after incubation.

\subsubsection{Permeation Experiment}

Separation performance of the produced membrane was evaluated in term of pure water flux, membrane permeability and solute rejection (vitamin $\mathrm{B} 12, \mathrm{NaCl}$ and $\mathrm{Na}_{2} \mathrm{SO}_{4}$ solutions). All the experiments were conducted by using Amicon stirred cell (Model 8200) at room temperature. For uncharged solute $(100 \mathrm{~g} / \mathrm{L}$ of vitamin $\mathrm{B} 12)$ and charged solute $(0.001 \mathrm{M} \mathrm{NaCl}$ and $0.001 \mathrm{M}$ $\mathrm{Na}_{2} \mathrm{SO}_{4}$ ), the stirring speed was held constant at $300 \mathrm{rpm}$ to minimize concentration polarization effect.

\subsubsection{Approximate Characterization Method using Uncharged Solute (Vitamin B12)}

For TFC nanofiltration membranes, effective pore radius $\left(r_{p}\right)$, and the ratio of effective membrane thickness over porosity $\left(\Delta x / A_{k}\right)$ are best characterized using approximate characterization method. Through this method, the flux and rejection data were fitted using the Donnan-Steric-Pore Model (DSPM) and HagenPoiseuille equation as described in previous studies $[15,16]$. For this study, $r_{p}$ was determined from the following equation by using vitamin B12 rejection data.

$R_{\text {real }}=1-\frac{C_{p}}{C_{w}}=1-\frac{K_{i, c} \Phi}{1-\exp \left(-P e_{m}\right)\left[1-\Phi K_{i, c}\right]}$

where the Peclet number, $P e_{m}$ is defined as:

$P e_{m}=\frac{K_{i, c}}{K_{i, d}} \frac{V \Delta x}{D_{i, \infty} A_{k}}$

$\Delta x / A_{k}$ is then determined based on following HagenPoiseeuille equation:

$$
J_{w}=\frac{r_{p}^{2} \Delta P}{8 \mu\left(\Delta x / A_{k}\right)}
$$

\section{Results and Discussion}

\subsection{UV-Vis Spectroscopy}

The formation of AgNPs was confirmed by using UVvisible spectroscopy (UV-vis). As shown in Figure 1, the peak observed the broad plasma resonance peak around at (a) $353 \mathrm{~nm}$ for the solution endures non-washing step while (b) $453.5 \mathrm{~nm}$ for the samples through the washing step. Similar result also found by other researcher [17].
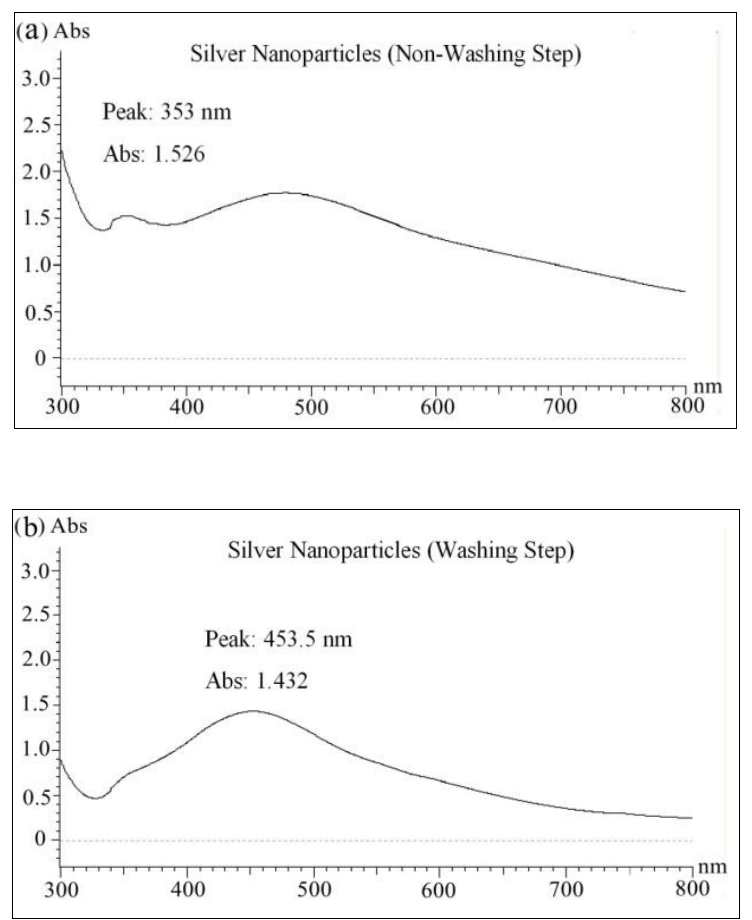

Fig. 1. UV/Vis spectrum shows the formation of AgNPs after 24 hours of reaction which the supernatant endured. (a) Nonwashing step (b) Washing step.

\subsection{Transmission Electron Microscopy (TEM)}

The size, shape and morphology of synthesized AgNPs were characterized by using TEM, and the image of AgNPs is shown in Figure 2. As can be seen in Figure 2, TEM image clearly shows that the morphology of AgNPs is nearly spherical in shape. Figure 3 displays the histogram of size distribution of AgNPs with sizes ranged from 10-80nm. About 64 particles were measured from the TEM image and the average particle size is $28 \pm 15 \mathrm{~nm}$. The difference in the particle size by TEM may be because of the nanoparticles were formed at different times.

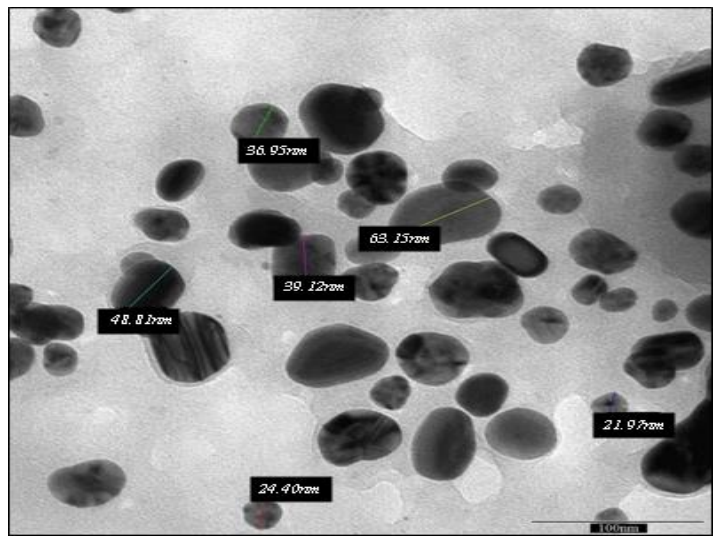

Fig. 2. TEM images of AgNPs 


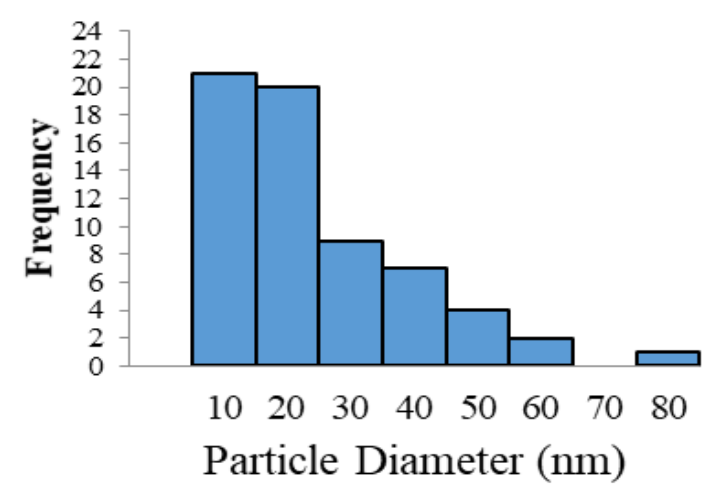

Fig. 3. The corresponding size distribution histogram of AgNPs

\subsection{X-ray Diffraction (XRD) analysis}

Figure 4 shows the XRD pattern of the Ag nanopowders obtained from the experiment. The pattern consists of three distinct peaks at corresponding $2 \theta$ values of $38.1^{\circ}$, $44.3^{\circ}$ and $64.5^{\circ}$. These values reveal that it is a facecentered cubic (fcc) structure. The discernible peaks can be indexed to (111), (200) and (220) planes of the cubic unit cell, which corresponds to the cubic structure of silver comparable to International Centre for Diffraction Data (ICDD), silver file No. 04-0783.

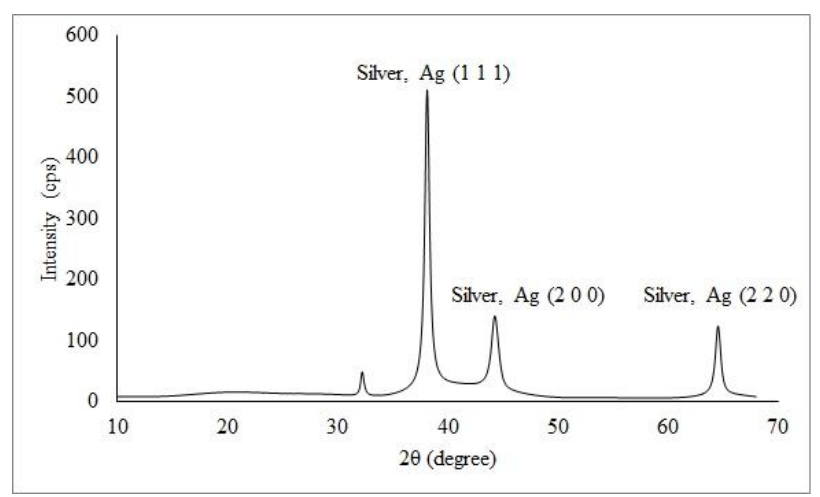

Fig. 4. XRD patterns of AgNPs

Debye-Scherrer equation was used to determine average crystallite diameter from half width of the diffraction peaks: Eq.4,

$$
\mathrm{D}=\mathrm{K} \lambda /(\beta \cos \theta)
$$

where D is the size of the particles $(\AA), \mathrm{K}$ is the shape dependent Scherrer's constant (1.05), $\beta$ ( $\mathrm{rad})$ is the full peak width, $\lambda$ is the wavelength of radiation, $(\theta \mathrm{rad})$ is the diffraction angle. The average crystallite sizes of synthesized AgNPs are listed in Table 2.
Table 2. Crystal sizes of AgNPs using Scherrer formula

\begin{tabular}{cc}
\hline Peak position & Average size (nm) \\
\hline $38.094^{\circ}\left(\begin{array}{lll}1 & 1 & 1\end{array}\right)$ & 21 \\
$44.230^{\circ}\left(\begin{array}{lll}2 & 0 & 0\end{array}\right)$ & 13 \\
$64.500^{\circ}\left(\begin{array}{lll}2 & 2 & 0\end{array}\right)$ & 19 \\
\hline
\end{tabular}

The crystal sizes of AgNPs as presented in Table 2 are very close or even smaller than the average value (28 $\mathrm{nm}$ ) obtained by TEM analysis. XRD size is usually equal or smaller than that obtained by TEM and similar result also observed by Akbari et al., when characterized the nanoparticles size [18]. The ( $\left.\begin{array}{lll}1 & 1 & 1\end{array}\right)$ plane was chosen as the average crystalline size of AgNPs since it showed an intense peak from XRD analysis. Therefore, the size of the AgNPs estimated from Debye-Scherrer formula is $21 \mathrm{~nm}$. The contradiction regarding the difference in the diameter between the value determined from the XRD patterns $(21 \mathrm{~nm})$ and the one from TEM observations (28 $\mathrm{nm}$ ) is unavoidable, as it was correlated with the limitations of the use of Debye-Seherrer formula, which is only applicable to near-spherical shape particles [19]. However, the difference in size between TEM and XRD analysis is too small. On top of that, it seems that the size of AgNPs crystal (in the range of 10-20 nm) as tabulated in Table 2 are represent the majority size of AgNPs analysed by TEM $(10 \mathrm{~nm}$ and $20 \mathrm{~nm}$ with the highest frequency; see Figure 3).

\subsection{Membrane Characterization}

\subsubsection{Antibacterial Assays of PA/Ag Membrane}

Disc diffusion method was used for susceptibility testing of $E$. coli bacteria. Literally, the antibacterial capability of produced PA/Ag NF membranes could be seen from the inhibition zone area.The results shown in Figure 5 are the antibacterial test on E. coli from this study and the antibacterial test results from Basri et al. [2]. Membrane (c) and (d) were produced through phase inversion technique with $0.54 \mathrm{wt} \%$ and $0.9 \mathrm{wt} \%$ of silver nanoparticles as deduced by EDX, respectively. Meanwhile, membrane (b) represent PA/Ag-60 was produced by IP with $0.7 \mathrm{wt} \%$ of silver nanoparticles.
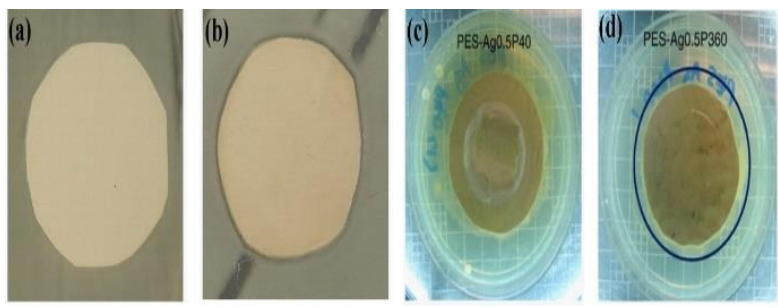

Fig. 5. Result of the Antibacterial Assays; (a) control PES (without AgNPs) [14] (b) PA/Ag-60 with $0.7 \mathrm{wt} \%$ AgNPs by EDX [14](c) PES-Ag0.5P40 with $0.54 \mathrm{wt} \%$ by EDX [2] (d) PES-Ag0.5P360 with $0.9 \mathrm{wt} \%$ by EDX [2].

Based on Figure 5, membrane (b) showed clearer inhibition zone compared to membrane (c) and (d) even 
the amounts of silver nanoparticles were approximately similar. Therefore, it makes IP as a promising technique to incorporate silver nanoparticles on the membrane surface.

\subsubsection{Characterization using Uncharged Solutes $\left(r_{p}\right.$ and $\Delta x / A_{k}$ parameter)}

Data of pure water permeability, vitamin B12 rejection, pore size $\left(r_{p}\right)$ and $\Delta x / A_{k}$ of six different types of membranes are listed in Table 3. The water permeation results show that the pure water permeability (PWP) for all membranes are in the range of reverse osmosis membrane [20]. However, pure water permeability alone is not enough to classify the type of membrane. Therefore, vitamin $\mathrm{B} 12$ rejection data was used to calculate the membrane pore size. The obtained pore size $\left(r_{p}\right)$ revealed that the values were in the range of 29 commercial available NF membranes studied by Bowen and Mohammad [15]. The lower pure water permeability may due to the fact that the thin layer form on the top surface is denser/compact and thicker than the commercial membrane. It can be clearly seen from the higher values of $\Delta x / A_{k}$ of the prepared membranes compared to commercial one (maximum $\Delta x / A_{k}=16.9 \mu \mathrm{m}$ [15]). However, the values of $\Delta x / A_{k}$ obtained in the current study are almost similar to the self- fabricated NF membranes as reported by Lau and Ismail [21]. Based on these two structural parameters, the prepared membranes in this study could be considered as tight NF membranes. In general, there is no specific correlation between reaction time and membrane structural parameters and water permeability. In addition, the presence of AgNPs also not significantly changes membrane performance.

Table 3. Permeability, Vitamin B12 rejection and Structural Parameters For Different Types of Membrane

\begin{tabular}{lrrrr}
\hline $\begin{array}{c}\text { Types } \\
\text { of } \\
\begin{array}{c}\text { Memb } \\
\text { rane }\end{array}\end{array}$ & $\begin{array}{c}\text { Permeability } \\
\left(\mathrm{L} / \mathrm{m}^{2} \text {.h.bar }\right)\end{array}$ & $\begin{array}{c}{ }^{+} \text {Vitamin } \\
\text { B12 } \\
\text { Rejection, } \\
R_{\text {real }, \%} \%\end{array}$ & ${ }^{*} r_{p}$ & ${ }^{* *} \Delta x / A_{k}$ \\
& & & \\
& & & & \\
\hline PA-10 & 0.435 & 75.77 & 1.3 & 198 \\
PA-30 & 0.619 & 65.00 & 1.4 & 176 \\
PA-60 & 0.434 & 70.02 & 1.3 & 229 \\
PA/Ag-10 & 0.294 & 85.54 & 1.1 & 223 \\
PA/Ag-30 & 0.429 & 73.49 & 1.3 & 212 \\
PA/Ag-60 & 0.475 & 56.53 & 1.6 & 292 \\
\hline
\end{tabular}

${ }^{+}$concentration of $100 \mathrm{mg} / \mathrm{L}$ tested at 4 bar

* calculated based on Eq (1)

** calculated based on Eq (3)

\subsubsection{Salt Rejection}

For salt rejection determination, the experiments were carried out with $0.001 \mathrm{M} \mathrm{NaCl}$ and $0.001 \mathrm{M} \mathrm{Na} \mathrm{Na}_{4}$ solutions at $400 \mathrm{kPa}$. The percentage rejection of both $\mathrm{NaCl}$ and $\mathrm{Na}_{2} \mathrm{SO}_{4}$ solutions for all types of the membrane were summarized in Figure 6.

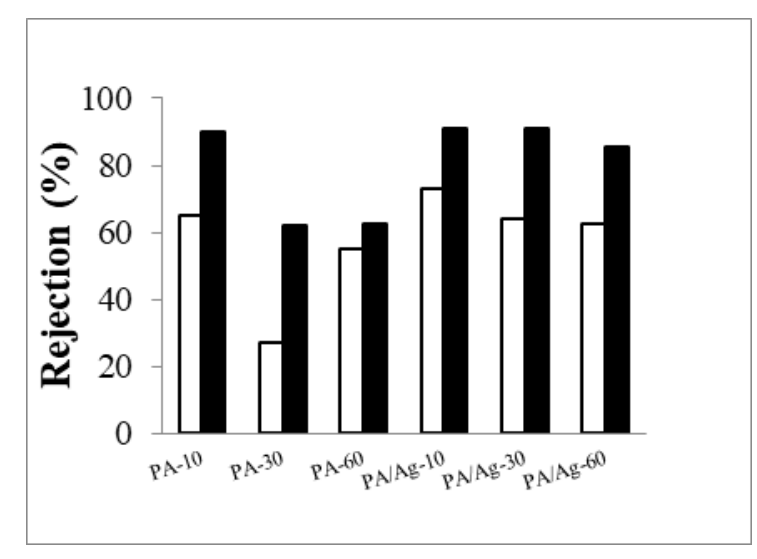

Fig. 6. Rejection of $0.001 \mathrm{M} \mathrm{NaCl}(\square)$ and $0.001 \mathrm{M} \mathrm{Na}_{2} \mathrm{SO}_{4}(\mathbf{\square})$ salt solutions at $400 \mathrm{kPa}$

PA/Ag membranes exhibited better salts removal than PA membrane. It can be clearly seen from Figure 6, higher rejection for both salts were obtained for all $\mathrm{PA} / \mathrm{Ag}$ membranes. In other words, the presence of AgNPs gives a positive impact on salt removal. Among all prepared membranes, PA/Ag-10 shows the highest rejection value of $73 \%$ and $91 \%$ for monovalent $(\mathrm{NaCl})$ and divalent salt $\left(\mathrm{Na}_{2} \mathrm{SO}_{4}\right)$, respectively. In general, for all available membranes, higher rejection was observed for divalent ions than monovalent ions, and this represents the characteristic of NF membrane [22,23]. This result strengthens our previous claim that the membranes prepared in this study are in the range of NF membranes.

\section{Conclusions}

AgNPs have been successfully synthesized by a green approach using tea leaves extract. The method used in this study is an efficient, simple and clearly a green method without using any harmful reducing and capping agents. The spectroscopic characterization from UVvisible, XRD and TEM supports the stability of the biosynthesized nanoparticles. PA and PA/Ag membranes were successfully prepared by interfacial polymerization of aqueous MPD and TMC organic solution. The membranes were characterized in term of water permeability, and structural parameters (pore size, $r_{p}$ and $\Delta x / A_{k}$ ) and results show that the membranes prepared were in the range of NF membranes. From salt rejection test, membranes with the addition of AgNPs exhibited higher salt rejection when compared to membranes without AgNPs. Among all six membranes, PA/Ag-10s membrane showed the highest $\mathrm{NaCl}$ and $\mathrm{Na}_{2} \mathrm{SO}_{4}$ salt rejection which is $73 \%$ and $91 \%$, respectively.

The authors wish to express thanks to Ministry of Education Malaysia through the financial aid from ERGS grant (RDU 130602) and MyBrain15. Appreciation is also expressed to all colleagues and technical staffs of FKKSA Lab, Universiti Malaysia Pahang for providing necessary facilities and guidance throughout this study. 


\section{References}

1. H.S. Lee, S.J. Im, J.H. Kim, H.J. Kim, J.P. Kim, B.R. Min, Desal. 219, 48 (2008)

2. H. Basri, A.F. Ismail, M. Aziz, Desal. 273, 72 (2011)

3. D.Y. Koseoglu-Imer, B. Kose, M. Altinbas, I. Koyuncu, J. Memb. Sci.428, 620 (2013)

4. J. Huang, G. Arthanareeswaran, K. Zhang, Desal. 285, 100 (2012)

5. A. Mollahosseini, A. Rahimpour, M. Jahamshahi, M. Peyravi, M. Khavarpour, Desal. 306, 41 (2012)

6. S.Y. Lee, H.J. Kim, R. Patel, S.J. Im, J.H.Kim, B.R. Min, Polym. Adv. Technol. 18, 562 (2007)

7. P. Kshirsagar, S.S. Sangaru, M.A. Malvindi, L. Martiradonna, R. Cingolani, P.P. Pompa, Colloids Surfaces A Physicochem. Eng. Asp. 392, 264 (2011)

8. P. Mohanpuria, N.K. Rana, S.K. Yadav, J. Nanoparticle Res. 10, 507 (2008)

9. J.-H. Li, X.-S. Shao, Q. Zhou, M.-Z. Li, Q.-Q. Zhang, Appl. Surf. Sci. 265, 663 (2013)

10. L. Mulfinger, S.D. Solomon, M. Bahadory, A.V. Jeyarajasingam, S.A. Rutkowsky, C. Boritz, J. Chem. Educ. 84, 322 (2007)

11. Q.H. Tran, V.Q. Nguyen, A.-T. Le, Adv. Nat. Sci. Nanosci. Nanotechnol. 4, 033001 (2013)

12. I. Kubo, M. Himejima, S. Chemical, J. Agric. Food Chem. 40, 245 (1992)

13. Y.Y. Loo, B.W. Chieng, M. Nishibuchi, S. Radu, Int. J. Nanomedicine. 7, 4263 (2012)

14. T.N.A.T. Sallehuddin, M.N. Abu Seman, Journal of Membr. Sci. and Res. 3, 29 (2017)

15. W.R. Bowen, A.W. Mohammad, Trans IChemE. 76, 885 (1998)

16. W.R. Bowen, A.W. Mohammad, N. Hilal, J. Memb. Sci. 126, 91 (1997)

17. N. Ahmad, S. Sharma, V.N. Singh, S.F. Shamsi, A. Fatma, B.R. Mehta, Biotechnol. Res. Int. 2011, 1 (2011)

18. B. Akbari, M.P. Tavandashti, M. Zandrahimi, Iran. J. Mater. Sci. Eng. 8, 48 (2011)

19. Z.H. Dhoondia, H. Chakraborty, Nanomater. Nanotechnol. 2, 15 (2012)

20. B.-H. Jeong, E.M.V. Hoek, Y. Yan, A. Subramani, X. Huang, G. Hurwitz, J. Memb. Sci. 294, 1 (2007)

21. W.J. Lau, A.F. Ismail, Journal of Memb. Sci. 334, 30 (2009)

22. J. Schaep, B.V. der Bruggen, S. Uytterhoeven, R. Croux, C. Vandecasteele, D. Wilms, E.V. Houtte, F. Vanlerberghe, Desal, 119, 295 (1998)

23. N. Hilal, H. A1-Zoubi, N.A. Darwish, A.W. Mohammad, Abu Arabi M., Desal. 170, 281 (2004) 